\title{
A Report Based on Analysis of Posture and Occupational Health of Welders in Different Welding Units
}

\author{
Das Suman $^{1, *}$, Banerjee Debamalya ${ }^{2}$, Mukherjee Shankarashis ${ }^{3}$ \\ ${ }^{1}$ Department of Mechanical Engineering, Swami Vivekananda Institute of Science \& Technology, India \\ ${ }^{2}$ Department of Production Engineering, Jadavpur University, India \\ ${ }^{3}$ Department of Physiology, University Colleges of Science and Technology, India
}

Copyright $@ 2018$ by authors, all rights reserved. Authors agree that this article remains permanently open access under the terms of the Creative Commons Attribution License 4.0 International License

\begin{abstract}
Analysis of work posture of workers is an effective research area in manufacturing sector in India. Manufacturing plays a significant role to develop a country. Lots of human involvements are required to successfully execute the various operations involved in this area. Long manual working hours with traditionally designed tools and un-ergonomic work posture can cause musculoskeletal disorders and other occupational health problems among welders. Prolonged working hours exceed the physical capacity of the workers that causes' discomfort, physical fatigue, joints pain, swelling, strain, sprain of ligaments and soft tissues. Work related musculoskeletal disorders (WRMSD) in the form of repetitive motion injuries, cumulative trauma disorders, body fatigue and strain injuries are very common health problems of workers of different small \& medium scale welding units in our country. The productivity and cost benefits of welding units are highly related with the physical comfort of the welders. The data of musculoskeletal disorder of workers of welding units was collected evaluated and validated by using RULA, OWAS and Discomfort Questionnaire and a design solution suggested.
\end{abstract}

Keywords Postural Analysis, RULA, OWAS, Welding, WRMSD

\section{Introduction}

Proper occupational hygiene, proper working environment and appropriate postural methods of the workers are highly neglected in small scale manufacturing sectors in our country. Welding is the most important part of manufacturing the products. Health and safety of workers are the significant issues in this unit now a day.
High productivity as well as maximum profit is the greatest interest of these industries. Target oriented work put some pressure on the workers that also increase their muscular and body fatigue. Welders are highly involved and also do their work in very bad body postures in this unit. Welding operation consists of cutting, drilling and joining the different steel sections in the work-stations. Work is performed on kneeling posture and the worker has to sit and execute the operation on a fixed jig \& fixture on the ground continuously [1, 2]. The pain in the different joints, ligaments muscles is very common physical problems of welders and they get fatigued frequently. Uncomfortable as well as unergonomic work postures and static nature of work create these types of musculoskeletal problems. More rapidly work-related diseases will come and musculoskeletal system will be collapsed if no ergonomics alertness taken among welders. The Work Related Musculoskeletal Disorders (WRMDs) occurred due to unscientific workstations design and negligence of ergonomics measures. Proper ergonomically design of work -station can increase the productivity, integration, workers comfort, worker variety and security \& safety up to a certain extent. Due to heavy weight and non-stop holding of welding gun, welders might not work properly for a long period of time. Work postures as well as physical load of welders can be measured and evaluated by using RULA and OWAS technique. There is a particular attention to the neck, trunk and upper limbs of the workers body for postural and whole body load calculation [3]. The objective of this research work is to analysis and evaluates the working postures of welders engaged in different welding units in the country. High RULA \& OWAS score indicate that posture was not granted for occupational health and safety of the welders. Product quality and efficiency of the welders will be reduced and body fatigue, muscular pain should be increased if no Ergonomic 
interventions among welders is taken. Ergonomically designed work station, proper planning and scientific body postures of welders can reduce these problems partially. The gap between the actual Ergonomic considerations and real practices at the work places give the view point to design the workstation. So the appropriate Ergonomics guidance and awareness programmers to the workers are essential to overcome work related musculoskeletal problems that will help to improve health and physical capabilities of the welders and finally the job quality.

\section{Background}

Workers in the welding sector experienced serious overexertion injuries at rates greater than the national average for all industries and all construction workers [4]. An array of technical, organizational and environmental challenges must be considered when developing and executing ergonomics interventions in the welding units. Injuries and illnesses of welders now a day are due to overexertion and constant static type of work. It is reported from studies that high rates of carpel tunnel syndrome (CST) has been observed among workers in welding trade and similar type of work [5]. The awareness and Ergonomic intervention in the unorganized sector is very low. So the MSDs are always present in small and medium scale enterprise where manual activities are carried out. Low back, neck, shoulder, fore arm and hands are the most commonly affected body regions due to that reason. Most of the work related MSDs are cumulative trauma disorders which result from exposures to high or low intensity loads acting over a long period of time repeatedly.

Proper Ergonomic interventions are the best solution to prevent work related musculoskeletal disorders and other health related problems among welders $[6,7]$. Unhygienic and poor environmental condition develops various occupational health dieses and musculoskeletal disorders among welders also. Occupational health problems and many diseases due to bad postures can be minimized by taking proper Ergonomic principals and training. The safety equipments like face shield, gloves apron and firstaid facility must be provided for protection of welders.

\section{CAD Modeling of Human Body}

3D CAD model of human body was developed with the help of solid works software. The model was exposed to ANSYS for analysis of stresses.

The upper part of the welder's body i.e. trunk, clavicles, upper arm, fore arm, neck and hands are connected by anatomically motivated restricted articulations which are directly involved with the welding operation. Pelvis, neck, shoulders, elbow, hip and wrists joints provide twenty (20) degree of freedom for the entire movement. Degree of freedom (DoF) of the joints which are involved in this operation is shown in table1.

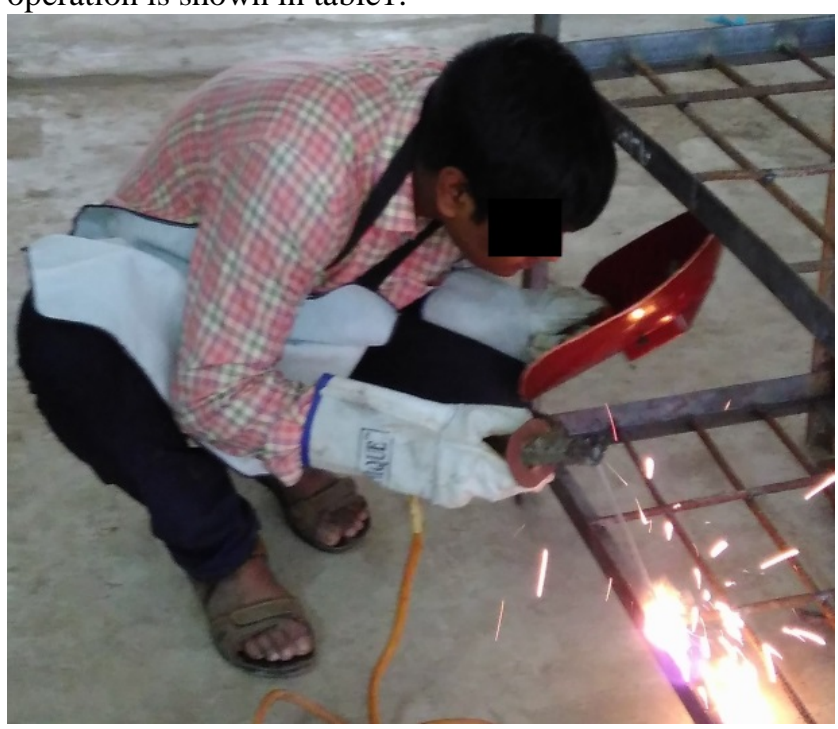

Figure 1. Working Posture of Welder

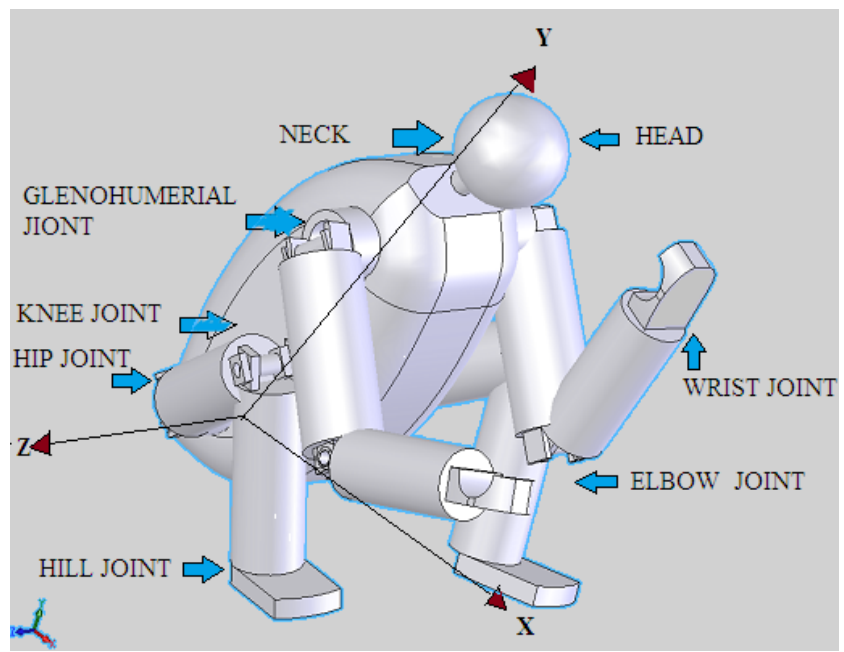

Figure 2. CAD model of welder's body with different joints

Table 1. Degree of Freedom of different joints

\begin{tabular}{|c|c|}
\hline Name of the Joint & Degree of Freedom \\
\hline Neck & 3 \\
\hline Each Shoulder Joint & 2 \\
\hline Pelvis Joint & 3 \\
\hline Each Elbow Joint & 1 \\
\hline Each Wrist Joint & 2 \\
\hline Each Hip Joint & 2 \\
\hline
\end{tabular}

\section{Methodology}

The research work was done in small scale welding units in West Bengal. The snap shot of 10 workers in different welding units were obtained and analyzed with the help of RULA, OWAS and Discomfort Questionnaires. 


\section{A. Postural Assessment}

Different techniques were applied for analysis of body postures of welders. These tools can be used to assess a variety of tasks, in any sitting position where body posture is static, dynamic or rapidly changing. This method is the quick survey method for use in Ergonomic interventions of work places where MSDs are reported. This assessment method can accesses bio-mechanical and postural loading of the workers body.

i) RULA Method: RULA method was developed by Lynn McAtamney and E Nigel Corlett in 1993. It helps to examine ergonomics especially upper limbs of the workers body in the work places. Musculoskeletal loads of the workers can be evaluated due to body postures, motion-repetition and force. No special equipments and tools are required for this assessment. An action is generated by using a coding system which indicates the level of intervention necessary to decrease the risk of injury due to physical loading of the workers. This method accomplished these goals by providing a "Grand Score" that can be categorized by Action Levels. Upper score indicating urgent changes to be made in the body posture for reducing muscular fatigued and also for improvement of job quality.

ii) OWAS Techniques: A steel industry company was developed this Ovako Working Posture Assessment System in 1977 in Finland. It was extensively used to identify and assess the harmful working postures. This method was based on a simple and systematic classification of work postures combined with observations of corresponding tasks. Postures were recorded according to a coding system, such that the code for a posture was a record of the posture itself, the load or force used and the stage in the cycle or task. The higher the numbers are, at any stage of the analysis, the further away from a desirable posture the posture under consideration. Based on the code numbers of each limb, an action category value is then determined.

\section{B. Questionnaires and Interview Technique}

The Questionnaires consist of questions pertaining to different problems related to this particular operation. Daily activity of the worker, discomfort level of different body parts, working and resting periods were plotted and calculated. NIOSH body discomfort survey was used for mapping and plotting different areas of pain of the body parts with its intensity. Body discomfort level can also be calculated with the help of this method.

\section{Framework and Flow Chart}

Occupational safety \& health are the major concerns in small scale units to improve the productivity and work quality. Some of the common problems are improper design, mismatch between worker abilities \& job demand and adverse environment.

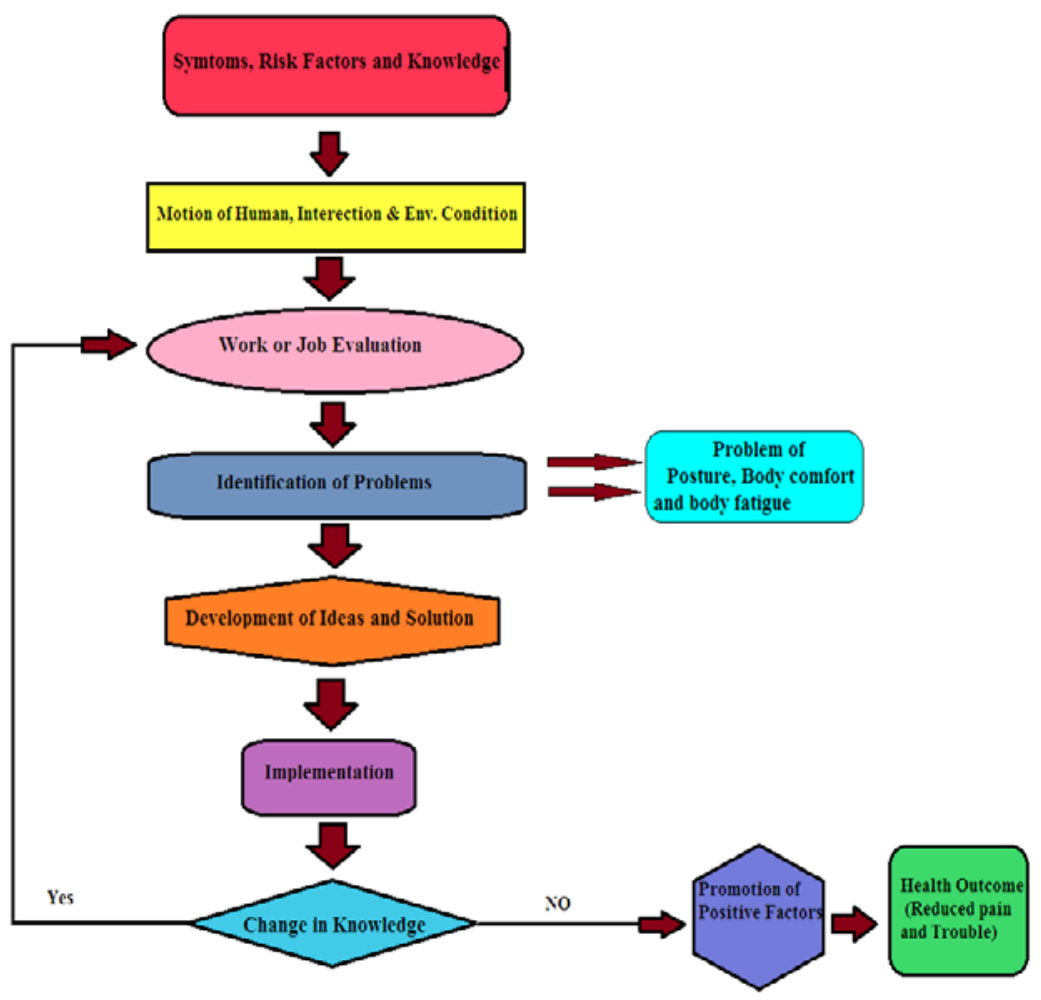

Figure 3. Framework and flow chart of health outcome 
It has been noticed that human factors improve the productivities, workers health, safety and job satisfaction. From this frame work and flow chart [Figure 3], it is clear that ergonomically designed machines and work stations can reduce muscular problems, physical fatigue and improve workers health. Proper Ergonomic knowledge, planning and awareness can also reduce physical and mental stresses.

\section{Results}

The result of RULA score indicates that the working postures of most of the workers were above the line indicated in the figure 4. Immediate change of Ergonomic intervention was needed of the welders. The result of this study revealed that the welding workers were engaged in manual handling jobs, leading to various muscular disorders primarily affecting the upper part of the body.

Present study also indicates that work related incidents affect different body parts of the welders. A good work posture is important for the performance of tasks as it is for promoting health and minimizing stress and discomfort during work [8, 9 and 10]. Ovako Working Posture Analysing System (OWAS) was used for analysing and evaluating the working postures adopted by the welders while performing the activities.

Figure 5 show that the low back pain, wrist and knee problems have the highest frequency caused by sitting on knee of the welders for a long period of time [11, 12]. The demographic data of the workers i.e. age, height working experience etc. are shown in the table 2 . The most prevalent symptoms of the welders were in their low back (43\%), knees (53\%) and wrist (53\%) due to inappropriate tools, work table and body posture [13, 14 and 15].

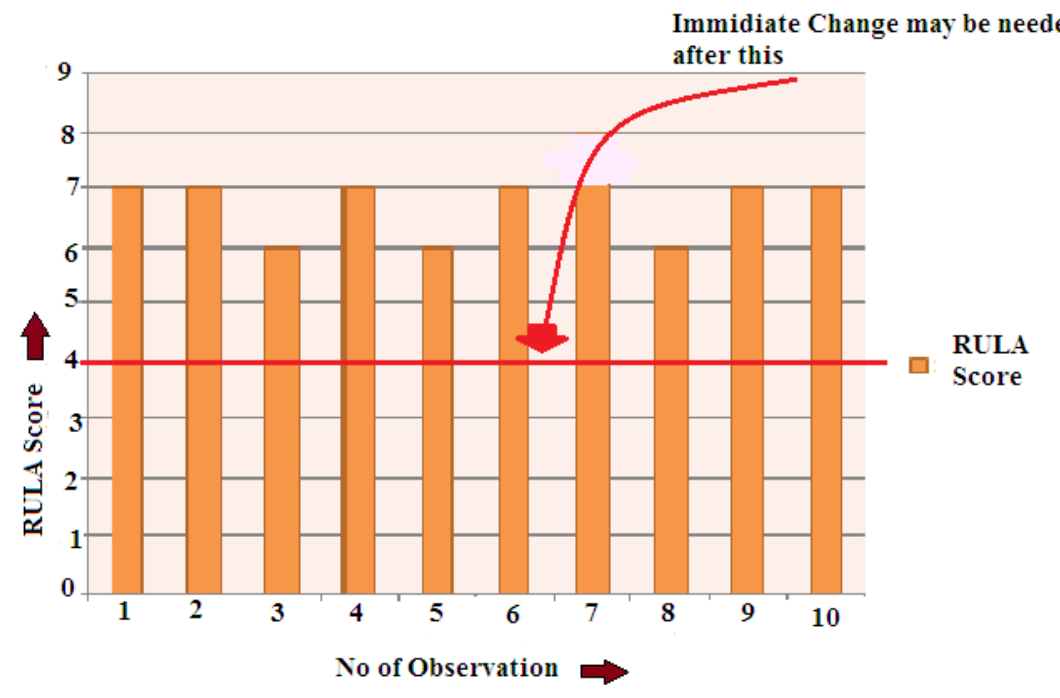

Figure 4. RULA Score of welders

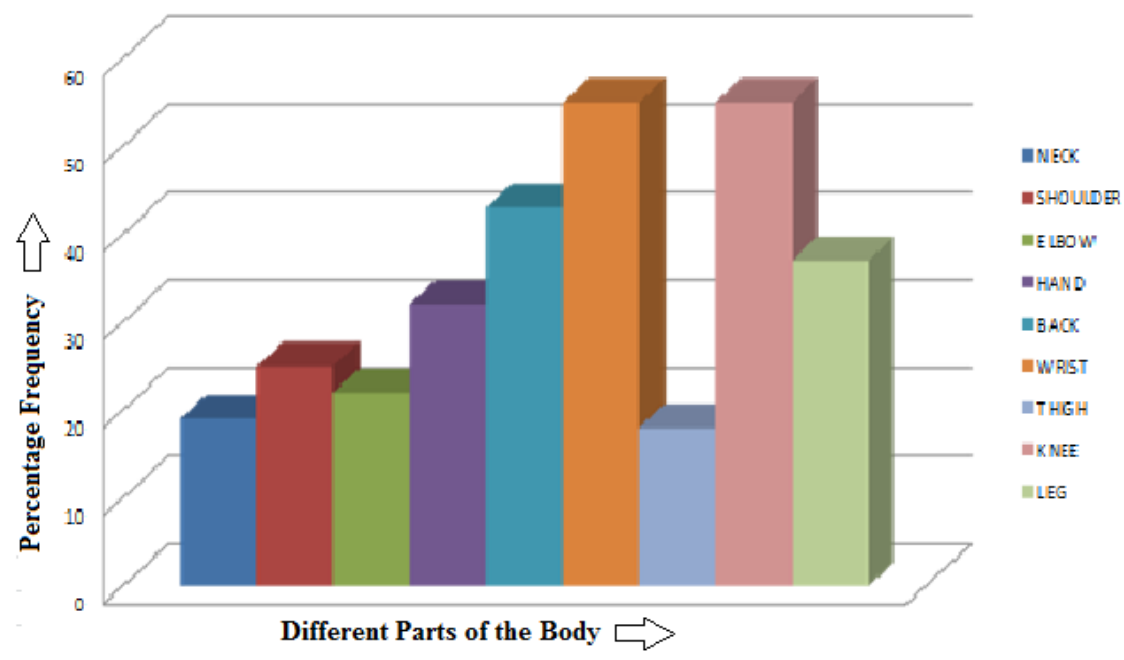

Figure 5. Frequency of musculoskeletal disorder of different body parts 
Table 2. Demographic data of the workers $(n=10)$

\begin{tabular}{|c|c|}
\hline Variables & WORKERS (SD) \\
\hline Mean Age (years) & $25.4( \pm 4.62)$ \\
Height (cm) & $167.35( \pm 3.35)$ \\
Mean working experience (years) & $5 \pm 2$ \\
\hline
\end{tabular}

NIOSH's discomfort survey method was used for plotting the different areas of pain, dissatisfactions of the welder's body during welding operation. Software Ergo-Fellow was used for the analysis. The following figures [Figure: 6, 7] show the different level of discomfort in different working hours in a day in terms of evaluation and frequency.

The figure 6 indicated the body discomfort level with respect to hours. In the $8^{\text {th }}$ hour the discomfort level changes markedly for being awaked worked posture for a long time. The level of discomfort in the $1^{\text {st }}$ working hour is within the acceptable range which exceeded beyond the severe level due to in appropriate body posture. It is shown that upper part of the welders' body is highly affected in the last working hour $[16,17]$. Red bars are indicating that these body parts are highly affected and could not be recovered in short time.

Neck, wrist, arms and upper part of the body are highly affected in this operation. More than $85 \%$ of the welders were got affected in their wrist, hand, trapeze and neck due to in appropriate position of electrode holder, body posture and unergonomic man machine interface.

\section{Discussion}

This research work gives a detailed knowledge on the occurrence of musculoskeletal complaints in welding operation and the features of the welding work stations. The significant results are discussed with the help of following points.

\subsection{Factor Associated with Musculoskeletal Symptoms}

It is observed that musculoskeletal symptom in different body regions are significantly associated with welding type, working posture, working time and type of seat. The individual factors like age, gender and marital status are also associated with musculoskeletal problems for each body region [18]. The major Ergonomic factors noticed to be associated with musculoskeletal problems that are discussed with the ultimate goal of developing guidelines for welding workstation design to improve working posture and to reduce postural stress.

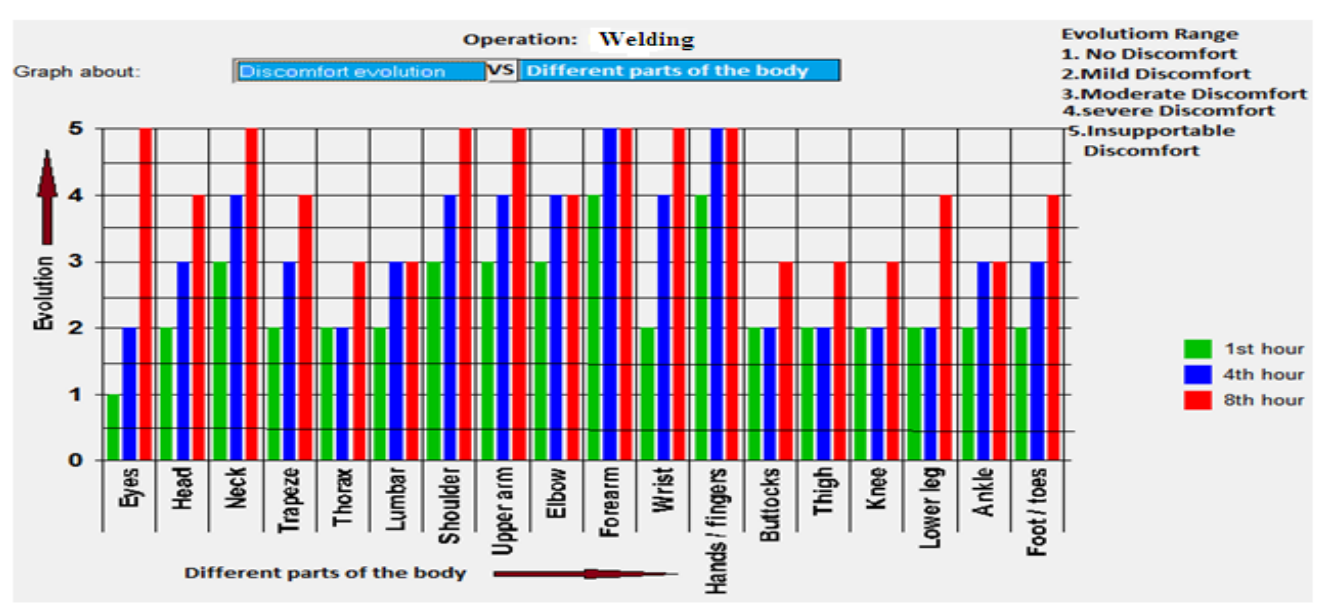

Figure 6. Discomfort Evolution in Different body parts

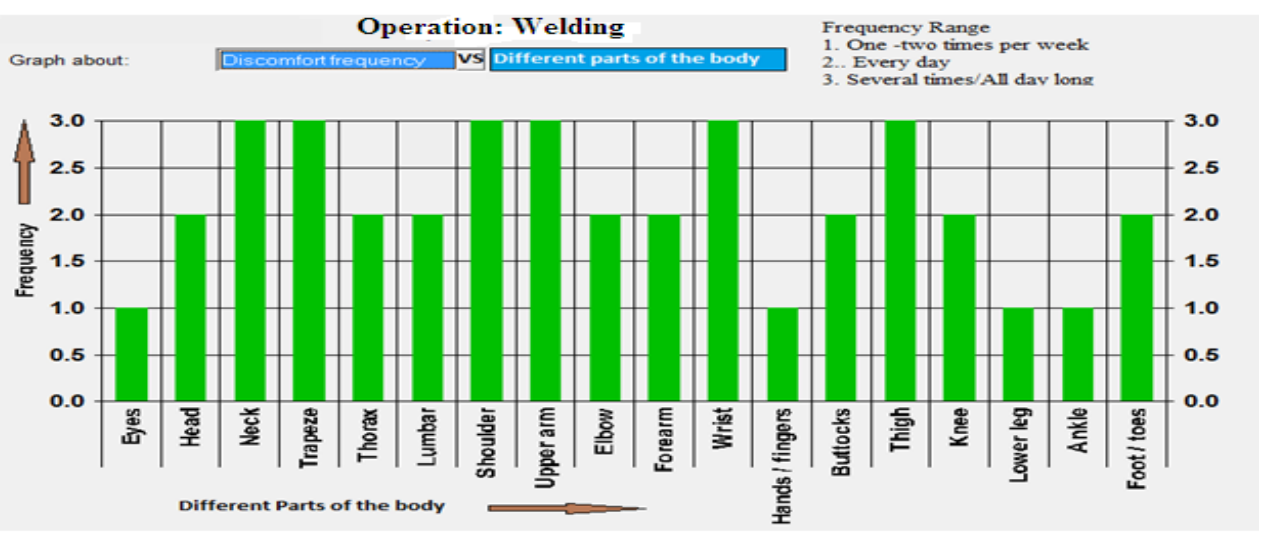

Figure 7. Discomfort Frequency in Different body parts 


\subsubsection{Welding Type}

From the figure-7 it is shown that the prevalence rates of discomfort symptoms in the neck, back, arms, shoulder and thighs are statically higher in this type of welding workers. The welding is done in welding units continuously on the ground for long period of time [Figure-1]. It is done on kneeling posture as the fixture used for welding is placed on the ground. It is observed that due to continuous welding the neck, back are bent considerably and knees are completely folded so that welders got fatigued and musculoskeletal problems are identified.

\subsubsection{Working Posture}

The working postures of the welders are stands for the posture of neck, trunk, hand and legs while working. As shown in figure-6, the pain in neck, back, wrist, hips, shoulders and arms increased significantly with increase in working hours and experiences. Lack of work station adjustability in welding operation can be the main cause of constrained and challenging posture. For ground welding operation the job table is the determinate factor for neck, shoulder and arm postures. No attention had been given to easy adjustability of the job table and its easy rotation. There is no specific welder's seat for the operation.

\subsubsection{Daily Working Time}

Daily working time is not usually fixed in welding units. Depending on the work load and situation it varies. Earning more money insist welders to work long period of time. Welders usually work continuously for a long period of time without rest or interval. This causes prolonged exposure to MSDs risk factors and an increased risk factor of sicknesses. More than $50 \%$ of the welders worked more than 8 hrs. /day and $20 \%$ of the welders worked 10 hrs./day or more. The result indicates that daily working hours have a direct association with MSDs symptoms and it is a significant factor for MSDs of all body parts of the welders.

\subsubsection{Welders Seat}

Welders' seat is one of the significant factors for MSDs of all body regions of the welding workers. From figure -1 it is shown that the posture of the knee is in folded type while welding. There is no appropriate seat in the work station during welding operation. From the Ergo Fellow software analysis [Figure-6\&7] and OWAS score [Figure-5] it is noted that musculoskeletal problems in the back, wrist, hands, legs and knees are occurred in a higher rates among those who take the sit on the ground in the folded knee posture. So seat and its type is the significant factor retained in the models for musculoskeletal symptoms.

\subsection{Prevalence of Musculoskeletal Symptoms}

The questionnaires show that musculoskeletal symptoms are common among welders. Operation in welding in different welding units can be considered as a high risk job for developing musculoskeletal syndromes [19].

Analysis shows that the prevalence rates of musculoskeletal symptoms of different body parts of welders are significantly different. On the basis of the results it is noticed that interventional ergonomic programme should be given higher priority to minimize the MSDs problems.

\subsection{Workstation Design Guidelines}

Based on the results of the present research work, the following recommendations are suggested as general ergonomic guidelines for design of welding work station. This guidance is towards the elimination of constraints, awkward postures and improving working conditions as well as job quality [20].

1. Welding height should be adjustable to permit natural working posture to the welders.

2. Welding workstation should be equipped with an appropriate welder's seat. The seat height should be adjustable.

3. Sufficient clearance must be provided for leg movement.

4. The controls for adjusting the physical dimensions of the welding workstation should be easy to handle.

\subsection{Application of the Guidelines and its Evaluation in a Prototype Workstation}

As per the workstation design guidelines and after a thorough study a CAD model of prototype welding workstation (job table and welder's seat) has been designed [figure:8]. The most important feature of the workstation is its adjustability. 


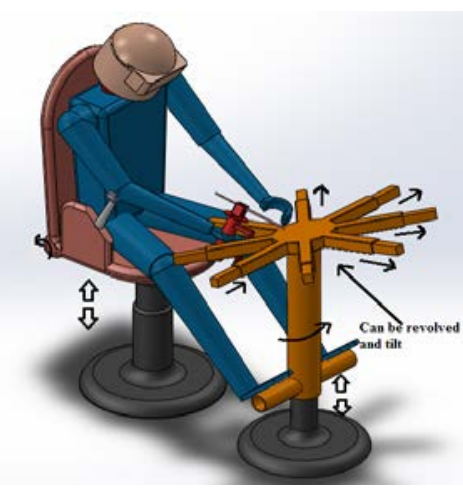

(a) 3-D View

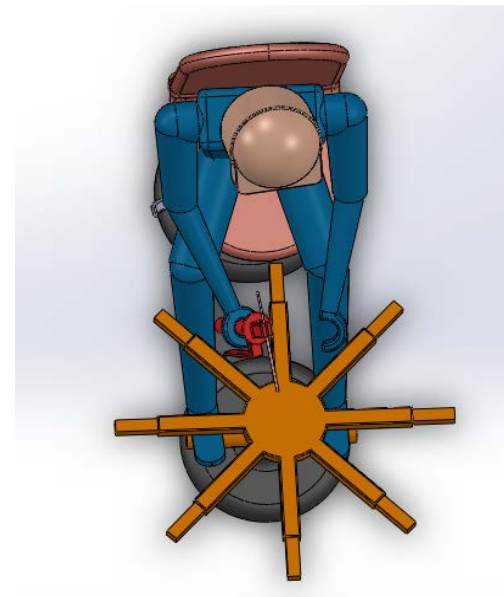

(c) Top View

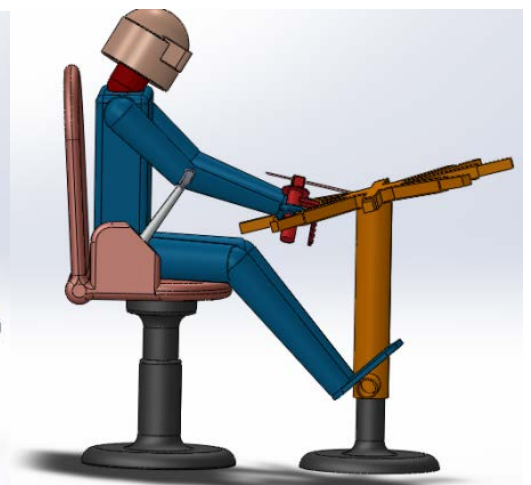

(b) Left side view

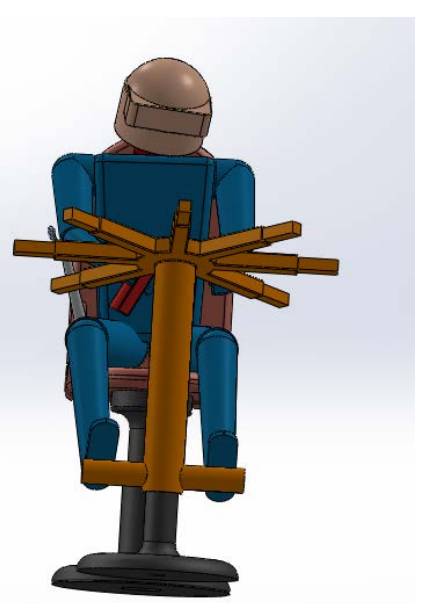

(d) Front view

Figure 8. Prototype Design of Welders Chair \& Job Table in Different Orientations developed in Solid Works software

It is seen that the job table was made of hollow rectangular channel [Figure: 8] having eight adjustable arms that can slide and change its length as per the requirement of the job. The top head of the table was mounted on a pipe and it can be revolved in any direction. The table head can tilt maximum $20^{\circ}$ towards the welders so that the trunk bent of the welders should be minimum. Figure- 8 shows that the height of the job table was adjustable also so that welders can adjust work level according to their preferences. This CAD model shows the comfortable posture of the welder's body which will reduces the RULA and OWAS score. It also decreases muscular stresses and body discomfort and finally improves the weld quality.

Adjustable chair with adjustable backrest was also used for adjusting the height with the job table as per requirement. The position of head, neck and arms shows that these were within the comfortable range. One foot rest and hand rest were provided for muscular comfort.

\section{Conclusions}

The optimization for postural prediction, fatigue, discomfort of different joints and its analysis was presented in this research work. It can be concluded that MSDs were present in the activities carried out in welding units where major number of workers were involved in bad body postures. The present research work shows that the poor working conditions enhance the MSDs of the workers. The several factors relating to the Ergonomic conditions were found to be important for enhancing the musculoskeletal symptoms. These were welding type, working posture, daily working time and seat type. Ill-designed workstation was the most important factor for MSDs symptoms in welding units. It was shown that modified and redesigned workstation will reduce the RULA and OWAS score. The new welding workstation based on designed guidelines will be acceptable to the welders and that will contribute to be an improved working posture. The prototype CAD model states that the new design will improve the working conditions and consequently may reduce prevalence of MSDs symptoms. This research work would be very useful for the workers working in any unorganized small scale unit. The body stresses, physical and mental fatigue of welders for this working process can also be validated and then integrated in to work evolution system in the future. 


\section{REFERENCES}

[1] Hignett, S. and McAtamney, L 2000 Rapid Entire Body assessment (REBA) Applied Ergonomics, 31, 201-205.

[2] Karhu, O., Kansi, P., and Kuorinka, I. 1977.Correcting working postures in industry: a practicalmethod for analysis. Applied Ergonomics, 8(4), 199201.

[3] D.C. Metgud, M.G. Mokashi, P.N. Saha, Subhash Khatri. An Ergonomics study of women workers in a woollen textile factory for identification of health-related problems.

[4] Aaras, A, G. Horgen, M. Helland. Can visual discomfort influence on muscle pain for visual display unit (VDU) workers.

[5] Rongo LM, et al. Occupational exposure and health problems in small-scale industry workers in Dares Salaam, Tanzania: a situation analysis. Occup Med (Lond), 2004; 54(1):42-6

[6] MarkkuMattila, Waldemar Karwowski \& Mika Vilkki. Analysis of working postures in hammering tasks on building construction sites using the computerized OWAS method. Applied Ergonomic,24(6): 405-412 (1993)

[7] Ali, A., Qutubuddin, S.M., Hebbal, S.S. and Kumar, A.C.S.(2011) “An Ergonomic Study of WorkRelated Musculoskeletal Disorders Among the Workers Working in Typical Indian Saw Mills" Intentional Journal of Engineering Research and Development, Vol.3, pp.38-45.

[8] Varmazyar Sakineh, et.al., "Evaluation Working posture and Musculoskeletal Disorders Prevalence in Pharmacy packaging Workers", European Journal of Scientific research ISSN 1450-216X vol.29 No. 1(2009), pp82-88.

[9] Widanarko, B., Stephen L., Stevenson, M., Devereux, J., Cheng, S. and Pearce, N. (2012) "Prevalence and work-related risk factors for reduced activities and absenteeism due to low back symptoms”, Applied Ergonomics, Vol. 43, pp. 727-737.

[10] Wearsted, M. Westgaard, RH. (1991)Working hours as a risk factor in the development of musculoskeletal complaints; Ergonomics Vol. 34(3) pp.265-76.

[11] Wall M de, Riel MPJM van, Snijders CJ, Wingerden JP van. "The effect on sitting posture of a desk with a 100 inclination for reading and writing” Ergonomics 1991; 34(5): 575-84

[12] Chavalitsakulchai P., Shahnavaz H., "Ergonomics method for preventions of musculoskeletal discomforts among the female industrial workers: Physical characteristics and work factors” Journal of Human Ergology, Nr 22,1993.

[13] Jaspreet Singh et al., "Musculoskeletal Disorder Risk Assessment in Small Scale Forging Industry by using REBA Method” International Journal of Engineering and Advanced Technology, Volume-1,Issue-5, June 2012.

[14] Jones, T. and Kumar S.(2010) “Comparison of ergonomic risk assessment output in four saw mill jobs” International Journal of Occupational Safety and Ergonomics, Vol. 16, No. 1 , pp.105- 111 .

[15] Gangopadhyay, S. and Dev, S. (2014) 'Design and Evaluation of Ergonomic Interventions for the Prevention of Musculoskeletal Disorders in India', Annals of Occupational and Environmental Medicine, Vol. 26, pp. 1-6

[16] Ashraf A. Shikdar, Naseem M. Sawaqed "Ergonomic, and occupational health and safety in the oil industry: a managers' response” Computers and Industrial Engineering vol.47 (2004) pp.223-232.

[17] Mostrighaci M., Salimi Z., Javaheri M., Hoseininejad S., Salehi M., Davari M., et al. "Evaluation of Musculoskeletal Disorders and its Risk Factors in the workers of an Agricultural Equipment - Manufacturing Plant”. Occupational Medicine Quarterly Journal 2012; 3(3): 19-25.

[18] Li, G., \& Buckle, P. (1999). “Current technique for assessing physical exposure to work-related musculoskeletal risks, with emphasis on posture- based methods". Ergonomics, 42(5), 674-695.

[19] Swangnetr M, Namkorn P, Phimphasak C, Saenlee K, Kaber $\mathrm{D}$, Buranruk O, et al. "Ergonomic analysis of rice field plowing” 1st ed. Boca Raton F, USA: CRC Press LLC: 2012. Chapter 64Advances in Physical Ergonomics and Safety PP. 565-574.

[20] Choobineh, A., Lahmi, M. and Shahnavaz, H. (2004) "Musculoskeletal symptoms as related to ergonomic factors in Iranian hand-woven carpet industry and general guidelines for workstation design”, International Journal of Occupational Safety and Ergonomics, Vol. 10, pp. 157-168. 